\title{
Measurement of digitalis-like compound in plasma: application in studies of essential hypertension
}

\author{
MARIE-AUDE DEVYNCK, MARIE-GABRIELLE PERNOLLET, JOSEPH B ROSENFELD, \\ PHILIPPE MEYER
}

\begin{abstract}
A digitalis-like compound was detected in human plasma by tritiated ouabain competition binding to the sodium pump. The study comprised analyses of plasma extracts from 17 normal controls, 17 normotensive subjects with one or both parents hypertensive, and 16 patients with untreated essential hypertension.

In two thirds of the untreated hypertensive and several of the normotensive subjects with a family history of hypertension the potency of the digitalis-like compound, as measured by its interference with ouabain binding, was significantly greater than in the controls. In the untreated hypertensive patients the potency of the compound was significantly correlated with the urinary sodium output.

Measurement of this salt-related, digitalis-like compound may be useful in clinical studies of hypertension.
\end{abstract}

\begin{abstract}
Introduction
Gradients in concentrations of monovalent sodium $\left(\mathrm{Na}^{+}\right)$and potassium $\left(\mathrm{K}^{+}\right)$between intracellular and extracellular fluids stem essentially from the activity of the sodium pump. This transport system plays an important part in regulating several cell functions, including control of cell volume, excitability, and nutrition. The sodium pump may be altered in certain pathological conditions, such as obesity ${ }^{1}$ and essential hypertension $^{2-4}$ and in various haematological disorders. 5 Dysfunction of the pump may originate from either intrinsic cell membrane alterations or the action of circulating factor(s) or
\end{abstract}

U7 INSERM, Departement de Pharmacologie, Hopital Necker, 75015 Paris, France

MARIE-AUDE DEVYNCK, PHD, maïtre de recherche au CMRS MARIE-GABRIELLE PERNOLLET, BSC, ingénieur à l'INSERM

JOSEPH B ROSENFELD, MD, visiting professor

PHILIPPE MEYER, MD, professor of pharmacology and director of department

Correspondence and requests for reprints to: Dr Marie-Aude Devynck. both. Endogenous pump inhibitors have been described in biological fluids ${ }^{7-10}$ and in tissues such as brain ${ }^{11-13}$ and kidney. ${ }^{1014}$ These factors appear to be increased by sodium loading and volume expansion both in animals and in man..$^{15-17}$ Several clinical and experimental investigations suggest that the reduction in sodium pump activity in primary hypertension may be secondary to an increased activity of such an inhibitor. ${ }^{16} 1 \mathrm{~s}$ The resulting increase in intracellular $\mathrm{Na}^{+}$may be of pathogenic significance.

The $\mathrm{Na}^{+}-\mathrm{K}^{+}$pump is inhibited by digitalis compounds, ${ }^{10}$ and specific binding sites for tritiated ouabain ( ${ }^{3} \mathrm{H}$-ouabain) have been detected on cell membranes. ${ }^{20} \mathrm{~A}$ substance capable of inhibiting the $\mathrm{Na}^{+}$pump might thus interact with the same sites. We have investigated the existence of such an inhibitor in normotensive and hypertensive subjects.

\section{Materials and methods \\ PREPARATION OF PLASMA EXTRACT}

Venous blood was collected into ice chilled tubes containing heparin and centrifuged for five minutes at a maximum of $3000 \mathrm{~g}$. Red cells and buffy coat were discarded and the plasma boiled immediately in a water bath for 15 minutes. In contrast to other methods 2122 we did not acidify the plasma before boiling and thus avoided $\mathrm{pH}$ induced changes such as modifications of affinities for carriers, complexing of cationic substances, or dissociation of protein subunits. The protein network was dislocated into small fragments and centrifuged at $50000 \mathrm{~g}$ for 15 minutes. A clear supernatant was obtained and either processed immediately or stored at $-80^{\circ} \mathrm{C}$ for later analysis.

\section{${ }^{3}$ H-OUABAIN BINDING TO ERYTHROCYTES}

${ }^{3} \mathrm{H}$-Ouabain ( 17 or $32 \mathrm{Ci} / \mathrm{mmol}$ ) was obtained from Amersham (UK) in a mixture of benzene and ethanol $(9 / 1)$. The organic solvents were evaporated under nitrogen and the residue taken up in a $10 \mathrm{mM}$, pH 7.4 trometamol-(TRIS)- $\mathrm{HCl}$ buffer. ${ }^{3} \mathrm{H}$-Ouabain binding was studied only on erythrocytes from normotensive subjects who did not have a family history of hypertension, thus avoiding possible membrane changes associated with hypertension.

Erythrocytes were separated by centrifugation $(3000 \mathrm{~g}$ for five minutes) and washed five times at $4^{\circ} \mathrm{C}$ in the following medium: 
$\mathrm{NaCl} 130 \mathrm{mmol}(\mathrm{mEq}) / 1$, sucrose $20 \mathrm{mmol} / 1(685 \mathrm{mg} / 100 \mathrm{ml})$, glucose $10 \mathrm{mmol} / 1(180 \mathrm{mg} / 100 \mathrm{ml})$, and trometamol $10 \mathrm{mmol} / 1(121 \mathrm{mg} / 100$ $\mathrm{ml}$ ) buffered with $\mathrm{HCl}$ to a $\mathrm{pH}$ of $7 \cdot 4$. Cells (packed cell volume ranging from 0.01 to 0.03 ) were incubated at $37^{\circ} \mathrm{C}$ for five hours in concentrations of ${ }^{3} \mathrm{H}$-ouabain ranging from $2 \times 10^{-9}$ to $2.5 \times 10^{-8} \mathrm{~mol} / 1$ $(0.2$ to $1.5 \mu \mathrm{g} / 100 \mathrm{ml})$. Parallel incubations were performed with the addition of an excess of unlabelled ouabain $\left(10^{-4} \mathrm{~mol} / 1 ; 5 \cdot 8 \mu \mathrm{g} / 100 \mathrm{ml}\right)$ to measure the non-saturable binding. Specific binding was taken as the difference between ${ }^{3} \mathrm{H}$-ouabain bound in the absence and presence of unlabelled ouabain. Bound and free radioactivity were separated by filtration through Whatman GFC filters washed with ice cold buffer. Radioactivity was counted in the presence of aci dified Instagel after treatment with $1 \mathrm{ml}$ Soluene 350 (Packard) and then with $0.5 \mathrm{ml}$ hydrogen peroxide (120 volume). Each binding study was performed using five ouabain concentrations, and binding parameters were calculated from linear regression of Scatchard plots. Under these experimental conditions ${ }^{3} \mathrm{H}$-ouabain binding to erythrocytes reached equilibrium within five hours and non-saturable binding accounted for less than $20 \%$ of total binding. Specific binding was saturable, and Scatchard analysis showed the presence of only one class of sites. characterised by an apparent dissociation constant of 2.? (SEM $0 \cdot 8) \times 10^{-9} \mathrm{~mol} / \mathrm{l}$ ) and a mean number of sites of 396 (SEM 27) per cell $(n=24)$. These values are close to those reported by other laboratories. ${ }^{21}$

Since plasma contains potassium ions known to inhibit ouabain binding, preliminary experiments were performed to estimate the variations of the affinity constant in the presence of potassium concentrations up to $1 \mathrm{mmol}(\mathrm{mEq}) / 1$. A significant change in affinity was observed only with potassium concentrations higher than $0.25 \mathrm{mmol} / 1$. Since the physiological plasma potassium concentration ranges from 3.5 to $5.0 \mathrm{mmol} / 1$ plasma extracts were analysed at a dilution of $1 / 20$. At that dilution the final $\mathrm{K}^{+}$concentrations in the incubation medium ( 1.175 to $0.25 \mathrm{mmol} / \mathrm{l}$ ) did not interfere with ouabain binding. Physiological concentrations of divalent calcium ions $\left(\mathrm{Ca}^{++}\right)$were also observed not to modify ouabain binding.

\section{PATIENTS AND CONTROLS}

Fifty white subjects were studied. Urinary sodium excretion was measured by flame spectrophotometry on urine collected during the night before blood sampling. Venous blood was sampled in the morning and blood pressure recorded with a mercury manometer in the sitting position. Subjects were divided into two groups of

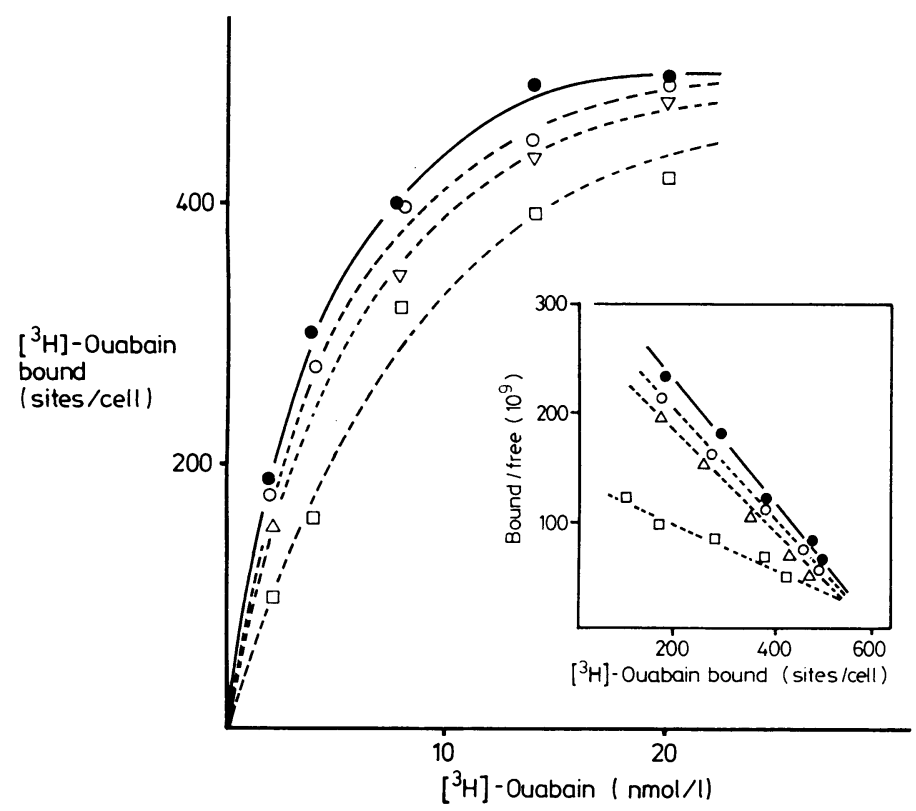

FIG 1-Ouabain binding to erythrocytes in absence (solid line, ( $O$ ) and presence (dotted lines) of plasma extracts from normotensive subject $(O)$ and two hypertensive patients $(\triangle \square)$. Equiliorium data as function of ouabain concentration.

Insert: Scatchard plots of same data indicating decrease in apparent affinity in presence of plasma.

Conversion: SI to traditional units-Ouabain: $1 \mathrm{nmol} / \mathrm{l} \approx 58.4 \mathrm{ng} / 100 \mathrm{ml}$.

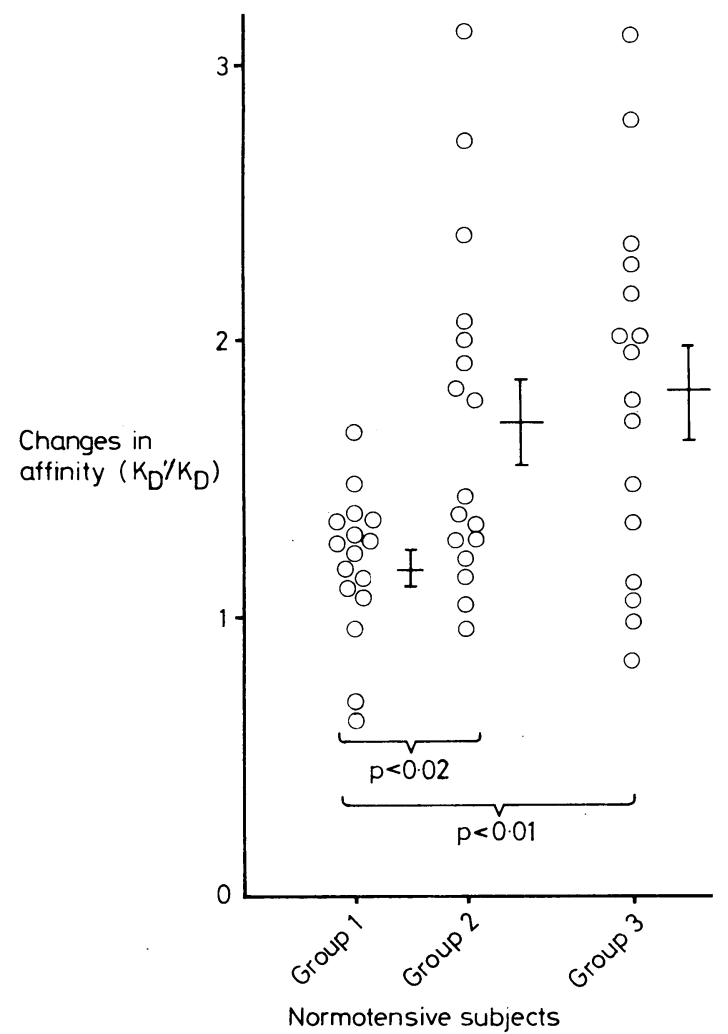

FIG 2-Inhibition of ouabain binding to erythrocytes by plasma extracts from hypertensive patients (group 3), and normotensive subjects with (group 2) and without (group 1) family history of hypertension. ( $\mathrm{K}_{\mathrm{D}}=$ Dissociation constant.) Bars are means (SEM).

normotensive subjects (groups 1 and 2) and one group of patients with untreated essential hypertension (group 3 ).

Group 1 comprised 17 normotensive volunteers with no known family history of hypertension. Eleven were men and six women, and their age range was 22-39 years (mean 29.4 (SEM 1.3)). Subjects were selected on the basis of $(a)$ systolic and diastolic blood pressures below 140 and $85 \mathrm{~mm} \mathrm{Hg}$, respectively, and $(b)$ blood pressures in relatives never exceeding $160 / 95 \mathrm{~mm} \mathrm{Hg}$. In addition, there was no reported case of hypertension among second degree relatives. Average blood pressure in the group was $121 \cdot 0$ (SEM 3.5)/79.1 (SEM 2.1) $\mathrm{mm} \mathrm{Hg}$.

Group 2 comprised 17 normotensive volunteers with a family history of hypertension. Of these, 10 were male and seven female, and their age range was $12-50$ years (mean 32.5 (SEM $2 \cdot 5$ )). In every subject at least one parent had high blood pressure. The average blood pressure in the group was $129 \cdot 1$ (SEM 5.5)/78.7 (SEM 1.9) $\mathrm{mm} \mathrm{Hg}$.

Group 3 comprised 16 patients with essential hypertension diagnosed after careful investigation including an intravenous pyelogram. Eleven of the patients were men and five women, and their age range was 22-71 years (mean $46 \cdot 3$ (SEM 4.0)). None had taken antihypertensive drugs for at least two weeks before blood sampling, and none had plasma creatinine concentrations above $100 \mu \mathrm{mol} / 1(1 \cdot 1 \mathrm{mg} / 100 \mathrm{ml})$ or noticeable retinal disturbances-for example, haemorrhage of papilloedema. Changes in the electrocardiogram suggestive of left ventricular hypertrophy were observed in 10 of the patients. In all patients plasma $\mathrm{Na}^{+}$and $\mathrm{K}^{+}$concentrations were within the normal range, with mean values of 139.2 (SEM 0.8 ) and $4 \cdot 1$ (SEM $0 \cdot 1$ ) $\mathrm{mmol} / 1$ respectively (extremes $136-143$ and $3 \cdot 6-4 \cdot 6 \mathrm{mmol} / \mathrm{l}$ ).

Statistical analysis was by unpaired Student's $t$ test.

\section{Results}

Plasma extracts inhibited ${ }^{3} \mathrm{H}$-ouabain binding to erythrocytes (fig 1). This inhibition was due to a decrease in the apparent affinity of ouabain for the $\mathrm{Na}^{+}$pump, with only minor changes in the binding capacity. Such an inhibition is characteristic of a competitive inhibitor The inhibitory effect of plasma extracts was expressed as the $K_{D}$ 
ratio-that is, the ratio of the apparent affinity constant measured in the presence of the extract to this constant measured in its absence. A high ratio thus indicated potent inhibition of ouabain binding.

\section{NORMOTENSIVE VOLUNTEERS}

The mean $\mathrm{K}_{\mathrm{D}}$ ratio in the two groups of normotensive subjects was 1.41 (SEM $0.10(n=91)$. Twenty seven values ranged between 0.6 and $1 \cdot 6$, but in seven of the 34 subjects the ratio exceeded $1 \cdot 7$. All seven subjects had a family history of hypertension (group 2).

When the two groups of normotensive subjects were considered separately, group 1 (no family history of hypertension) showed a mean $K_{D}$ ratio of $1.15(\operatorname{SEM} 0.07)(n=16)$ and group 2 (positive family history) a mean ratio of $1 \cdot 71($ SEM $0 \cdot 16)(n=15)$. The difference between these values was significant $(\mathrm{p}<0.01)$ despite the wide scatter in group 2 (fig 2).

\section{PATIENTS WITH ESSENTIAL HYPERTENSION}

Plasma extracts from the hypertensive patients inhibited competitive ${ }^{3} \mathrm{H}$-ouabain binding. Six of the 16 patients tested showed slight inhibitory effects, similar to those of the normotensive subjects with no family history of hypertension, whereas the other 10 plasma extracts were potent inhibitors (fig 2). The mean $K_{D}$ ratio in the hypertensive patients was 1.83 (SEM 0.21$)(n=16)$. This value was significantly different from that in the normotensive subjects $(p<0.02)$.

In the hypertensive patients the inhibition of ouabain binding was independent of age and sex, whereas a slight relation existed with systolic blood pressure $(r=0.44)$ and there was a significant correlation with urinary sodium output $(\mathrm{p}<0.01)$ (fig 3 ).

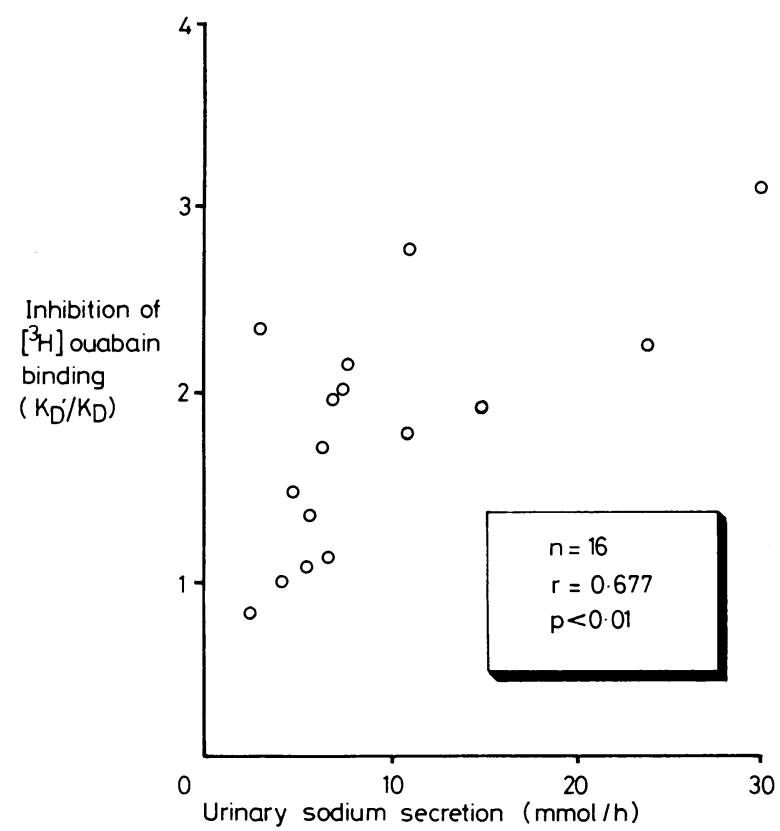

FIG 3-Correlation of inhibition by plasma extracts of ${ }^{3} \mathrm{H}$ ouabain binding to erythrocytes and urinary sodium output in patients with essential hypertension. ( $K_{D}=$ Dissociation constant.)

Conversion: SI to traditional units-Sodium: $1 \mathrm{mmol}=1 \mathrm{mEq}$.

\section{Discussion}

Several authors have proposed that endogenous inhibitors of the sodium pump have both a physiological role as regulators of sodium reabsorption during $\mathrm{Na}^{+}$loading or volaemic expansion $^{15-17}$ and a pathogenic role in essential hypertension. ${ }^{16}$ Taken by itself the presence of specific binding sites for digitalis compounds in the $\mathrm{Na}^{+}$pump is an argument for the existence of endogenous pump regulators sharing some structural characteristics with the cardiac glycosides. Our study shows that some plasmas indeed exert an inhibitory effect on ouabain binding.
This is compatible with suggestions of the existence of an endogenous pump inhibitor. This inhibitory effect is not mediated by vanadate or calcium ions, which are known endogenous inhibitors of the pump ${ }^{23} 24$ but do not prevent ouabain binding. ${ }^{25}$ Potassium ions also cannot be incriminated. The plasma inhibitor of ouabain binding is heat stable, as were other endogenous inhibitors of the $\mathrm{Na}^{+}$pump described. ${ }^{821}$

The point of clinical interest is the finding of an increased inhibitory effect in many hypertensive patients and some normotensive subjects with one or both parents hypertensive as compared with normotensive controls. The significant inhibition observed in the patients with essential hypertension agrees with other reports of increased levels of inhibitors of $\mathrm{Na}^{+}-\mathrm{K}^{+}-$ adenosine triphosphatase (ATPase), the enzymatic expression of the sodium pump. ${ }^{21}{ }^{26}$

The plasma inhibitory effect on ouabain binding was slightly more pronounced in patients with the highest blood pressures, similar to the findings in $\mathrm{Na}^{+}-\mathrm{K}^{+}-$ATPase inhibition studies. ${ }^{21}$ A more significant correlation was observed with urinary sodium output: the higher the sodium intake, the greater the inhibition of ouabain binding. This observation, which agrees with previous findings, ${ }^{16} 27$ argues for a relation between the sodium pump inhibitor and the regulation of sodium balance.

Our data support the hypothesis of MacGregor and colleagues, ${ }^{28}$ whereby an important pathological role in hypertension was attributed to an endogenous sodium pump inhibitor. The increase in intracellular sodium resulting from inhibition of the pump could, in excitable cells exhibiting $\mathrm{Ca}^{++}-\mathrm{Na}^{+}$ exchange, lead to enrichment of intracellular $\mathrm{Ca}^{++}$, which might represent the basis of the haemodynamic changes of hypertension. Our investigation, however, suggests that the increase in circulating digitalis-like compound may not be as constant as suggested by those authors. Hence multiple mechanisms may be implicated. An increased level of pump inhibitor may thus be of specific clinical interest, which justifies use of our method.

Finding increased inhibition of ouabain binding in some normotensive offspring of hypertensive subjects agrees with the reports of Ambrosioni et $a l^{28}$ and Heagerty et $a l^{29}$ who observed an increased intralymphocytic sodium concentration and reduced ouabain sensitive sodium fluxes in subjects with normal blood pressure and a family history of hypertension. That finding is difficult to explain. The change may be secondary to environmental influences and particularly to dietary habits such as high sodium intake. But it may also be of genetic origin. Whether or not a genetically related inhibition of the sodium pump is a prerequisite for high blood pressure remains unclear and merits further investigation. Here also the described methodology may prove to be of help.

\section{References}

1 De Luize M, Blackburn GL, Flier JS. Reduced activity of the red cell sodium-potassium pump in human obesity. N Engl f Med 1980;303: 1017-22.

2 Wambach G, Helber A. Na, K-ATPase in erythrocyte ghosts is not a marker for primary hypertension. Clin Exp Hypertens 1981 ;3:663-73.

${ }^{3}$ Postnov YV, Orlov SN, Shevchenko A, Adler AM. Altered sodium permeability, calcium binding and $\mathrm{Na}, \mathrm{K}$-ATPase activity in the red blood cell membrane in essential hypertension. Pfluegers Arch 1977;371:263-9.

- Edmonson RPS, Thomas RD, Hilton PJ, Patrick J, Jones NF. Abnormal leucocyte composition and sodium transport in essential hypertension. Lancet $1975 ; \mathrm{i}: 1003-5$.

5 Wiley JS, Ellory JC, Shuman MA, Shaller CC, Cooper RH. Characteristics of the membrane defect in the hereditary stomatocytosis syndrome. Blood $1975 ; 46: 337-56$

${ }^{6}$ Parker JC, Welt LG. Pathological alterations of cation movements in red blood cells. Arch Intern Med 1972;129:320-32.

${ }^{7}$ Clarckson EM, Raw SM, De Wardener HE. Two natriuretic substances in extracts of urine from normal man when salt-depleted and saltloaded. Kidney Int 1979;16:710-21.

${ }^{3}$ Gruber KA, Whitaker JM, Buckalew VM Jr. Endogenous digitalis-like substance in plasma of volume-expanded dogs. Nature $1980 ; 287: 743-5$.

${ }^{\vartheta}$ Licht A, Stein S, McGregor CW, Bourgoignie JJ, Bricker NS. Progress in isolation and purification of an inhibitor of sodium transport obtained from dog urine. Kidney Int 1982;21:339-44.

10 Kramer HJ. Natriuretic hormone, a circulating inhibitor of sodium and 
potassium activated adenosine triphosphatase. Klin Wochenschr 1981; 58: $1225-30$.

$"$ Haupert GT, Sancho JM. Sodium transport inhibitor from bovine hypothalamus. Proc Natl Acad Sci USA 1979;76:4658-60.

12 Fishman M. Endogenous digitalis-like activity in mammalian brain. Proc Natl Acad Sci USA 1979;76:4661-3.

13 Lichstein D, Samuelov S. Membrane potential changes induced by the ouabain-like compound extracted from mammalian brain. Proc Natl Acad Sci USA 1982;79:1453-6.

14 Raghavan SR, Gonick HC. Partial purification and characterization of natriuretic factor from rat kidney. Proc Soc Exp Biol Med 1980;164:101-

15 Haddy FJ, Pamnani MB, Clough DL. Humoral factors and the sodiumpotassium pump in volume-expanded hypertension. Life Sci 1979;24: 2105-17.

16 De Wardener HE, Clarkson EM, Bitensky L, MacGregor GA, AlaghbandZadeh J, Chayen J. Effect of sodium intake on ability of human plasma to inhibit renal $\mathrm{Na}, \mathrm{K}$-adenosine triphosphatase in vitro. Lancet $1981 ; \mathrm{i}: 411-2$.

17 Gonick HC, Kramer HJ, Paul W, Lu R. Circulating inhibitor of sodiumpotassium activated adenosine triphosphatase after expansion of extracellular fluid volume in rats. Clin Sci Mol Med 1977;53:329-34

18 Blaustein MP. Sodium ions, calcium ions, blood pressure regulation and hypertension: a reassessment and a hypothesis. Am F Physiol 1977;232: C165-73.

10 Glynn IM. The action of cardiac glycosides on ion movements. Pharmacol Rev $1964 ; 1 \mathbf{b}: 381-407$

${ }^{20}$ Matsui H, Schwartz A. Mechanism of cardiac glycoside inhibition of the $\mathrm{Na}, \mathrm{K}$-dependent ATPase from cardiac tissue. Biochim Biophys Acto $1968 ; 151: 655-63$.
"Hamlyn JM, Ringel R, Schaeffer J, et al. A circulating inhibitor of $\mathrm{Na}$, K -ATPase associated with essential hypertension. Nature 1982;300. 650-2.

${ }^{22}$ Gruber KA, Rudel LR, Bullock BC. Increased circulating levels of an endogenous digoxin-like factor in hypertensive monkeys. Hypertension $1982 ; 4: 348-54$.

23 Skou JC. The influence of some cations on adenosine triphosphatase from peripheral nerves. Biochim Biophys Acta 1957;23:394-400.

24 Cantley LC, Cantley LG, Josephson L. A characterization of vanadate interactions with the Na, K-ATPase. 7 Biol Chem 1978;253:7361-8.

${ }^{25}$ Myers TD, Boerth RC, Post RL. Effects of vanadate on ouabain binding and inhibition of $\mathrm{Na}^{+}, \mathrm{K}^{+}-\mathrm{ATPase}$. Biochim Biophys Acta 1979;558: 99-107.

${ }^{28}$ MacGregor G, Fenton S, Alaghband-Zadeh J, Markandu N, Roulston J, De Wardener $\mathrm{H}$. Evidence for a raised concentration of a circulating sodium transport inhibitor in essential hypertension. $\mathrm{Br}$ Med 7 1981; $283: 1355-7$.

27 Meyer P, Garay RP, De Mendonça M. Ion transport systems in hypertension. In: Genest J, Kuchel O, Hamet P, Cantin M, eds. Hypertension, physiopathology and treatment. New York: MacGraw Hill Book Company (in press).

${ }^{28}$ Ambrosioni E, Costa FC, Montebugnoli L, Tartagni F, Magnani B. Increased intralymphocytic sodium content in essential hypertension: an index of impaired $\mathrm{Na}^{+}$cellular metabolism. Clin Sci 1981;61:181-6.

${ }^{29}$ Heagerty AM, Milner M, Bing RF, Thurston H, Swales JD. Leucocyte membrane sodium transport in normotensive populations: dissociation of abnormalities of sodium efflux from raised blood pressure. Lancet 1982 ; : :894-6.

(Accepted 14 April 1983)

\title{
"Reciprocal" depression of the ST segment in acute myocardial infarction
}

\author{
KEVIN JENNINGS，DOUGLAS S REID，DESMOND G JULIAN
}

\begin{abstract}
In acute myocardial infarction depression of the ST segment in leads distant from those showing ST elevation has been considered to be "reciprocal" but might reflect local ischaemia. To examine this possibility 103 consecutive patients who underwent exercise testing early after myocardial infarction were reviewed. Treadmill exercise testing was performed a mean of 12 (range 5-30) days after infarction using a limited Naughton protocol. Thirty five $(34 \%)$ of the patients had had reciprocal change, defined as $\geqslant 1 \mathrm{~mm}$ ST depression in leads remote from the site of the infarct, within 48 hours of infarction. Twenty two $(63 \%)$ of the 35 patients developed exercise induced ST depression in the leads previously showing reciprocal change. Coronary artery disease was assessed in 10 of these patients by arteriography and in four at necropsy: all but one had stenosis of $\geqslant 50 \%$ in a coronary artery supplying the reciprocal territory in addition to the disease in the vessel to the infarct site. Of patients with reciprocal ST depression, $23.5 \%$ experienced nonfatal reinfarction, pulmonary oedema after discharge, or death compared with only $9.5 \%$ of patients without reciprocal ST depression. Eight (23.5\%) patients with
\end{abstract}

Cardiology Department, Freeman Hospital, Newcastle upon Tyne, NE7 7DN

KEVIN JENNINGS, MB, MRCP, senior registrar

DOUGLAS S REID, MB, FRCP, consultant cardiologis

DESMOND G JULIAN, MD, FRCP, professor of cardiology

Correspondence to: Dr K Jennings, Cardiology Department, Aberdeen Royal Infirmary, Foresterhill, Aberdeen. reciprocal depression had ventricular fibrillation while in hospital compared with only two $(3 \%)$ patients without.

Reciprocal ST depression in acute myocardial infarction may reflect ischaemia in territory distant from the site of infarction and is associated with a high risk of fatal arrhythmias and late morbidity.

\section{Introduction}

In acute myocardial infarction typical electrocardiographic elevation of the ST segment is often accompanied by depression of the ST segment in leads remote from the infarct site. This ST depression has long been regarded as an electrical phenomenon, the ST depression merely reflecting the ST elevation on the opposite side of the heart, and has been termed "reciprocal". ${ }^{2}$ While there is no doubt that these reciprocal changes can occur, this location of ST depression might in some cases reflect ischaemia in the territory of the ST change either distant from or adjacent to the infarct site. ${ }^{3-5}$ There are several reasons why ST depression may not be reciprocal. Firstly, it is not always present even when ST elevation is extreme: fig 1 shows two electrocardiograms from different patients with acute anterior infarction. In the first tracing (fig $1 a$ ) in addition to $13 \mathrm{~mm} \mathrm{ST}$ elevation there is ST depression in leads II, III, and aVF. In the second tracing, however, despite ST elevation of $25 \mathrm{~mm}$ there is no accompanying ST depression in the inferior leads. Secondly, when ST depression is present it does not always have the same time course as the ST elevation.

This raises the possibility that in some cases the ST depression may not be reciprocal but may reflect myocardial ischaemia on the opposite side of the heart. There are several mechanisms that might contribute to this ischaemia. If a patient with a myocardial infarction has multivessel disease ${ }^{\beta}$ an acute coronary 